\title{
PENGEMBANGAN GAME LABIRIN BERBASIS VIRTUAL REALITY UNTUK PENGENALAN PARIBASA BALI
}

\section{Gusti Kade Ari Satria Putra1, I Made Ardwi Pradnyana2, Gede Aditra Pradnyana3}

1 Prodi Pendidikan Teknik Informatika Jurusan Tektik Informatika Fakultas Teknik dan Kejuruan Universitas Pendidikan Ganesha, Jln. Udayana No.11 Singaraja 81116 INDONESIA

2 Prodi Sistem Informasi Jurusan Teknik Informatika Fakultas Teknik dan Kejuruan Universitas Pendidikan Ganesha, JIn. Udayana No. 11 Singaraja 81116 INDONESIA

3 Prodi Sistem Informasi Jurusan Teknik Informatika Fakultas Teknik dan Kejuruan Universitas Pendidikan Ganesha, JIn. Udayana No. 11 Singaraja 81116 INDONESIA

\begin{abstract}
Abstrak
Mengenalkan peribahasa Bali untuk melestarikan budaya bali menjadi hal yang perlu diperhatikan saat ini. Pengembangan permainan peribahasa Bali dalam bentuk labirin merupakan salah satu sarana untuk mengenalkan jenis-jenis paribasa Bali yang sudah berkembang di kalangan masyarakat umum. Pada permainan labirin paribasa Bali ini pemain dapat melihat jenis-jenis paribasa Bali dalam bentuk 3 dimensi dan juga bukubuku paribasa Bali dalam bentuk 3 dimensi. Pengembangan Game Labirin Paribasa Bali ini menggunakan metode $A D D I E$. Ada lima tahap dalam metode $A D D I E$ yaitu Analisis (Analysis), Desain (Design), Pengembangan (Development), Implementasi (Implementation) dan tahap Evaluasi (Evaluation). Pengembangan produk dengan metode ADDIE menghasilkan produk yang baik, karena pada setiap tahapan yang sudah dilalui, peneliti telah melakukan evaluasi dan revisi. Pengujian yang telah dilakukan seperti pengujian respon pengguna, yang pengujiannya difokuskan ke masyarakat umum yang berupa penyebaran angket dan mendapatkan hasil dengan persentase rata - rata sebesar 91\%, yang artinya aplikasi termasuk kedalam kategori sangat baik.
\end{abstract}

Kata Kunci:

$V R$, Labirin, Paribasa Bali, ADDIE

\begin{abstract}
Introducing a Balinese prolingual to preserve Bali's culture to be worth noting today. Development of Balinese language games in the form of a maze is one of the means to introduce the types of Balinese Paribasa that has developed among the general public. In this Bali Paribasa Maze game players can see the type - the type of Balinese Paribasa in the form of 3-dimensional and also books - Books of Balinese Paribasa in the form of 3 dimensions. The development of this Bali Paribasa Maze Game uses the ADDIE method. There are five stages in the ADDIE method, namely analysis (Analysis), design, development, implementation and evaluation stage. Product development with ADDIE method produce a good product, because at every stage that has been passed, researchers have conducted evaluation and revision. Tests that have been done like user response testing, which tests are focused on the general public in the form of poll distribution and get a result with an average percentage of $91 \%$, which means that the app belongs to the category very well.
\end{abstract}

\section{Keywords: \\ VR, Labyrinth, Balinese \\ Proverbs, ADDIE}

\section{PENDAHULUAN}

Budaya memiliki peran yang sangat penting bagi semua masyarakat, khususnya masyarakat Bali. Budaya dalam masyarakat Bali sangat dipegang teguh dari lahir hingga meninggal dunia. Menurut Edward Burnett Tylor, budaya adalah keseluruhan dari yang rumit atau kompleks yang di dalamnya telah

\footnotetext{
* Korespondensi

E-mail: arisatria049@gmail.com,ardwi.pradnyana@undiksha.ac.id,gede.aditra@undiksha.ac.id
} 
terkandung kesenian, moral, adat - istiadat, hukum, kepercayaan, pengetahuan dan berupa kemampuan kemampuan yang lain yang diterima dari seseorang yang menjadi masyarakat (Kurniawan, 2020). Tradisi - tradisi budaya adalah roh agama karena ia memiliki nilai - nilai yang ditanamkan oleh agama di dalam masyarakat. Budaya tercermin dalam karakter suatu masyarakat dan anggotanya. Tradisi - tradisi budaya berulang dan menjadi sebuah kebiasaan bagi setiap masyarakat (Wati, Darmawiguna, \& Putrama, 2016). Generasi muda pada zaman sekarang sudah dipengaruhi oleh modernisasi dan pengaruh budaya asing yang semakin gencar (Telusur, 2017). Mereka sudah mulai meninggalkan bahasa ibu yaitu bahasa Bali (Jundi, 2018). Bahasa merupakan wadah dan wahana bagi kebudayaan Bali. Paribasa Bali merupakan salah satu aspek dari wujud kebudayaan Bali, yang mengandung nilai-nilai luhur serta berpengaruh bagi pandangan hidup masyarakat penuturnya (Tinggen, 1994). Pada implementasinya sekarang, generasi muda lebih banyak dan terbiasa menggunakan bahasa Indonesia sebagai bahasa sehari-hari, dan tidak sedikit juga yang menggunakan bahasa asing, dibandingkan dengan menggunakan bahasa ibu yaitu bahasa Bali. Penggunaan bahasa asing yang semakin masif dan digunakan oleh masyarakat mayoritas menyebabkan bahasa Bali semakin terpinggirkan. Selain itu, hal tersebut juga menyebabkan kalangan muda menjadi kurang fasih dalam menggunakan bahasa Bali dalam komunikasi sehari-hari (Marantika \& Putra, 2017). Dengan perkembangan teknologi pada zaman sekarang kita bisa memanfaatkan teknologi tersebut menjadi media pembelajaran namun tidak menghilangkan budaya Bali itu sendiri (Indra, Darmawiguna, \& Arthana, 2015). Salah satu teknologi yang bisa digunakan virtual reality. Virtual reality merupakan sebuah teknologi yang dapat membuat pengguna melakukan interaksi dengan lingkungan $3 D$ yang dapat disimulasikan dengan komputer (Sulistyowati \& Rachman, 2017). Penulis memutuskan untuk membuat sebuah media yang digunakan untuk mengenalkan budaya paribasa Bali lebih dalam. Maka dari itu penulis memilih game sebagai media pengenalan paribasa Bali. Game dipilih karena merupakan salah satu media alternative untuk memperkenalkan budaya Indonesia yang semakin terlupakan, game juga sangat mudah diterima disemua kalangan dan sangat diminati oleh anak - anak (Renavitasari, Irawati, \& Prasetyo, 2016). Game yang akan dikembangkan adalah game 3 dimensi labirin yang menggunakan teknologi Virtual Reality (VR). Permainan labirin dipilih karena dapat melatih kecerdasan otak, kreativitas, dan pengetahuan (Bhaskara, Buana, \& Purnawan, 2017). Kecerdasan otak yaitu dalam hal menemukan jalan keluar saat menjelajahi labirin, sedangkan pengetahuan yang akan diberikan yaitu pengetahuan tentang paribasa Bali yang ada di Bali saat ini. Paribasa Bali ini digunakan sebagai petunjuk pada permainan labirin, dan petunjuk ini akan menuntun pengguna menuju jalan keluar. Permainan 3 dimensi dipilih karena dapat menarik minat pengguna untuk memainkan permainan ini, karena permainan yang bersifat 3 dimensi akan membuat permainan menjadi lebih nyata dan menarik (Apriyanto \& Lasodi, 2016). Berdasarkan latar belakang maka permasalahan yang didapat yaitu bagaimana membuat game yang dapat memberikan pengetahuan tentang paribasa Bali. Tujuannya yaitu memperkenalkan dan membangkitkan semangat generasi muda untuk mengedepankan bahasa ibu, yaitu bahasa Bali.

\section{METODE}

Pengembangan Game Labirin Berbasis Virtual Reality untuk Pengenalan Paribasa Bali berbasis Android ini menggunakan metode ADDIE. Prosedur pengembangan dalam model ADDIE terdiri dari lima tahap. Kelima tahap tersebut adalah analyze (analisis), design (desain), develop (pengembangan), implement (implementasi), dan evaluate (evaluasi) (Ganesan, 2015).

1. Analisis

Desain tahap analisis berfokus pada target audiens. Pada tahap analisis, dilakukan pendefinisian permasalahan instruksional, tujuan instruksional, sasaran pembelajaran serta dilakukan identifikasi lingkungan pembelajaran dan pengetahuan yang dimiliki.

2. Desain

Tahap desain terkait dengan penentuan sasaran, instrumen penilaian, latihan, konten, dan analisis yang terkait materi pembelajaran, rencana pembelajaran dan pemilihan media. Fase desain dilakukan secara sistematis dan spesifik.

3. Pengembangan

Dalam tahan pengembangan dilakukan pembuatan dan penggabungan konten yang sudah dirancang pada tahapan desain. Pada fase ini dibuat storyboard, penulisan konten dan perancangan grafis yang diperlukan.

4. Implementasi

Fase ini, dibuat prosedur untuk pelatihan bagi peserta pelatihan dan instrukturnya/ fasilitator. Pelatihan bagi fasilitator meliputi materi kurikulum, hasil pembelajaran yang diharapkan, metode penyampaian dan prosedur pengujian. 
5. Evaluasi

Setiap tahap proses $A D D I E$ melibatkan evaluasi formatif. Ini adalah multidimensional dan merupakan komponen penting dari proses $A D D I E$. Ini mengasumsikan bentuk evaluasi formatif dalam tahap pengembangan. Evaluasi dilakukan selama tahap implementasi dengan bantuan instruktur (Putra \& Nugroho, 2016). Tahapan metode ADDIE dapat dilihat pada Gambar 1.

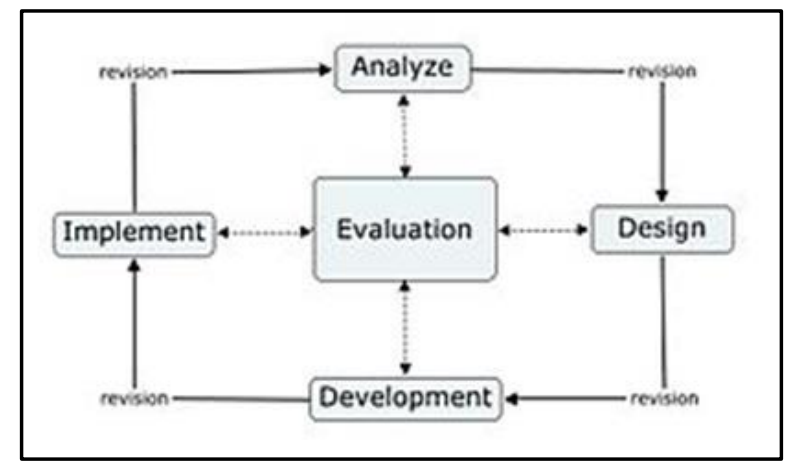

Gambar 1. Tahapan dalam metode ADDIE (Sumber: Instructionaldesign.org).

\section{HASIL DAN PEMBAHASAN}

Hasil evaluasi model penelitian merupakan proses menjalankan dan mengevaluasi sebuah perangkat lunak berdasarkan model penelitian yang digunakan untuk menguji apakah perangkat lunak sudah memenuhi persyaratan atau belum untuk menentukan perbedaan antara hasil yang diharapkan dengan hasil sebenarnya. Berikut ini akan dijabarkan mengenai beberapa tahapan terkait dengan hasil evaluasi dari Pengembangan Game Labirin Virtual Reality Untuk Pengenalan Paribasa Bali diantaranya yaitu tahap Analisis (analysis), tahap Desain (design), tahap Pengembangan (Development), tahap Implementasi (Implementation), dan tahap Evaluasi (Evaluation).

\section{A. Analisis}

Penulis mengumpulkan data dari buku dan jurnal tentang Peribahasa/Paribasa Bali. Paribasa Bali bila dilihat dari sudut struktur paribasa itu ternyata memiliki beberapa variasi yang agak berbeda satu dengan yang lainnya. Mengenai pembagian jenis-jenis paribasa Bali ini belum mendapat keseragaman, banyak perbedaan pendapat mengenai pembagian paribasa Bali itu sendiri. Peneliti sastrawan yang ikut mengemukakan pendapat tentang paribasa Bali antara lain : I.G.K. Ranuh, I Kt. Ginarsa, I. Kt. Suwija, dan I W. Simpen AB. Dari banyaknya perbedaan pendapat yang dikemukakan oleh sastrawan di atas, maka diambil suatu simpulan bahwa hanya ada enam jenis yang termasuk paribasa Bali itu yaitu : a. sesenggakan, b. sesonggan, c. sloka, d. wewangsalan, e. bladbadan, f. sesawangan. Kalau ditinjau dari kesekian banyaknya Paribasa Bali itu, maka ternyata kesemua bentuk itu merupakan metafora yang memainkan peranan penting dalam bahasa kias (Tinggen, 1994). Penulis juga membuat pemetaan tentang Paribasa Bali ketika diterapkan dalam sebuah game/permainan Virtual Reality dapat dilihat pada Tabel 1.

Tabel 1. Pemetaan penerapan paribasa Bali

\begin{tabular}{cc}
\hline Buku karangan I Nengah Tinggen & Penerapan pada game \\
\hline Stage 1 & $\begin{array}{c}\text { Pada stage 1 pemain mengenal } \\
\text { sesenggakan dan contohnya }\end{array}$ \\
Halaman 24 Sesenggakan & $\begin{array}{c}\text { Pada stage 1 pemain mengenal sesonggan } \\
\text { dan contohnya }\end{array}$ \\
Halaman 25 Sesonggan & $\begin{array}{c}\text { contohnya } \\
\text { Stage } 2\end{array}$ \\
Halaman 22 Sloka & $\begin{array}{c}\text { Pada stage 2 pemain mengenal } \\
\text { wewangsalan dan contohnya }\end{array}$ \\
Halaman 30 Wewangsalan & $\begin{array}{c}\text { Pada stage 3 pemain mengenal bladbadan } \\
\text { dan contohnya }\end{array}$ \\
\hline Stage 3
\end{tabular}




\begin{tabular}{cc}
\hline Buku karangan I Nengah Tinggen & Penerapan pada game \\
\hline Halaman 19 Sesawangan & $\begin{array}{c}\text { Pada stage } 3 \text { pemain mengenal } \\
\text { sesawangan dan contohnya }\end{array}$ \\
\hline
\end{tabular}

Penelitian terkait dilakukan oleh Sang Gde Aditya Bhaskara yang mengembangkan permainan edukasi labirin virtual reality dengan metode collision detection dan stereoscopic. Pada permaian yang dikembangkan, pemain akan diberikan berupa pertanyaan - pertanyaan umum. Apabila pertanyaan bisa dijawab, maka pemain akan mendapat petunjuk untuk menemukan jalan keluar. Selain itu pada permainan ini disediakan 8 level permainan. Kontrol permainannya menggunakan sensor Accelerometer dan sensor Gyroscope (Bhaskara et al., 2017).

\section{B. Desain}

Berdasarkan model $A D D I E$, pada tahap desain ini, penulis membuat rancangan dari aplikasi. Pada pengembangan Game Labirin Berbasis Virtual Reality untuk Pengenalan Paribasa Bali ini, penulis telah merancang model Fungsional Perangkat Lunak, struktur navigasi, aturan permainan, dan rancangan antarmuka.

1. Model Fungsional Perangkat Lunak

Untuk mentranslasi kebutuhan perangkat lunak ke representasi desain agar dapat diimplementasikan menjadi program pada tahap selanjutnya diperlukan diagram. Diagram adalah yang menggambarkan permasalahan maupun solusi dari permasalahan. Dalam pengembangan game ini, penulis menggunakan dua macam diagram yaitu use case diagram, dan activity diagram.

2. Use Case Diagram

Use Case Diagram merupakan sebuah teknik yang digunakan dalam pengembangan sebuah software atau sistem informasi untuk menangkap kebutuhan fungsional dari sistem yang bersangkutan (Prayudi, Arthana, \& Wirawan, 2015). Berikut adalah use case diagram dari Aplikasi Game Labirin Berbasis Virtual Reality untuk Pengenalan Paribasa Bali. Use case diagram dapat dilihat pada Gambar 2.

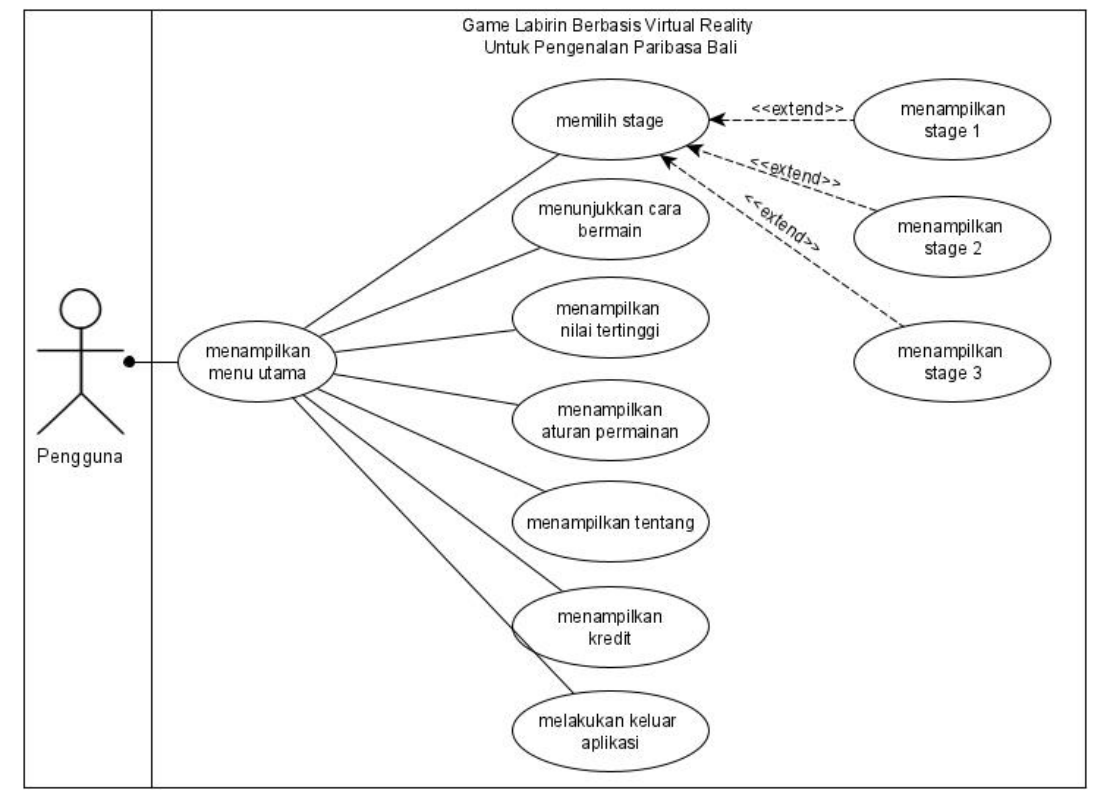

Gambar 2. Use case diagram aplikasi

\section{Activity Diagram}

Diagram activity menunjukkan aktivitas aplikasi dalam bentuk kumpulan aksi - aksi, bagaimana masing - masing aksi tersebut dimulai, keputusan yang mungkin terjadi hingga berakhirnya aksi. Activity diagram juga dapat menggambarkan proses lebih dari satu aksi salam waktu bersamaan. Diagram activity adalah aktifitas - aktifitas, objek, state, transisi state dan event. Dengan kata lain kegiatan diagram alur kerja menggambarkan perilaku sistem untuk aktivitas (Haviluddin, 2011). Berikut adalah activity diagram dari Game Labirin Berbasis Virtual Reality untuk Pengenalan Paribasa Bali yang terdiri dari memilih stage, cara bermain, nilai tertinggi, aturan permainan, tentang aplikasi dan keluar aplikasi. 

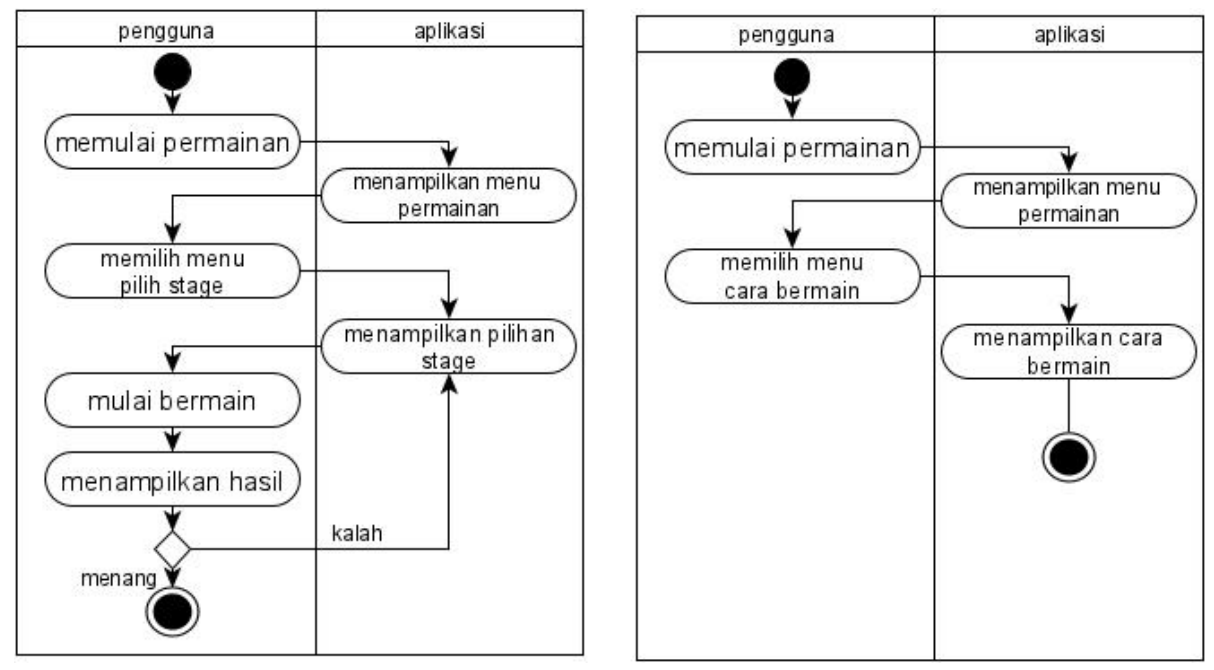

Gambar 3. Activity diagram memilih stage dan cara bermain
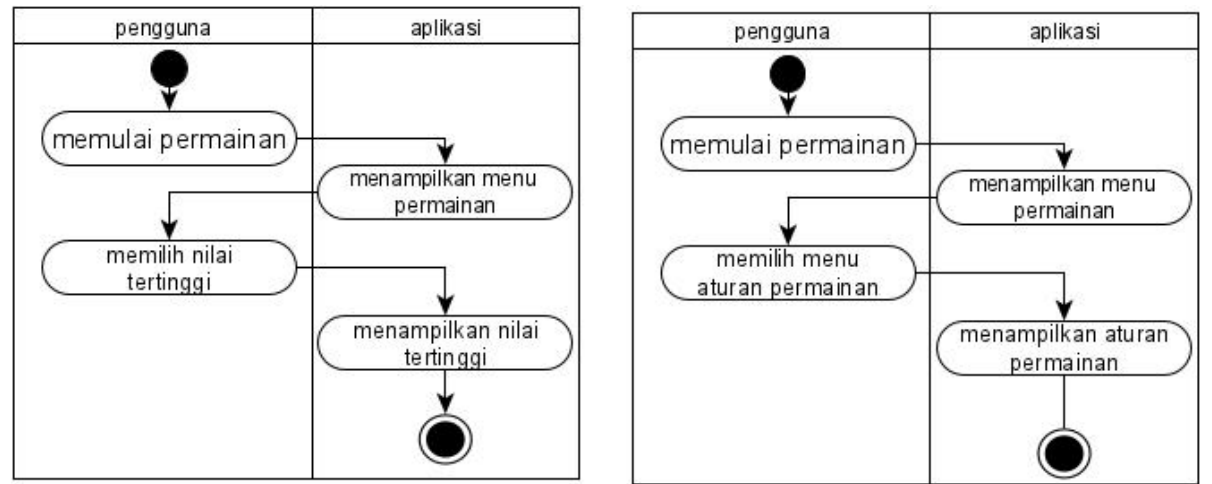

Gambar 4. Activity diagram nilai tertinggi dan aturan permainan
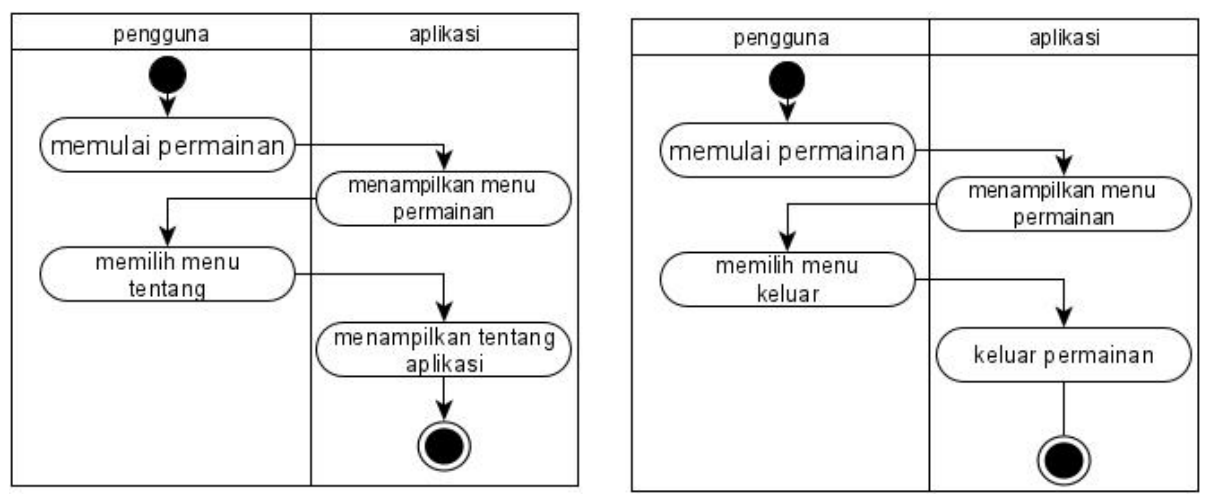

Gambar 5. Activity diagram tentang aplikasi dan keluar aplikasi

4. Perancangan Struktur Navigasi Perangkat Lunak

Struktur Navigasi merupakan struktur atau alur dari suatu program. Struktur Navigasi juga memberikan kemudahan dalam menganalisa keinteraktifan seluruh objek dalam aplikasi dan bagaimana pengaruh keinteraktifannya terhadap pengguna. Rancangan struktur navigasi pengembangan Game Labirin Berbasis Virtual Reality untuk Pengenalan Paribasa Bali dapat dilihat pada Gambar 6. 


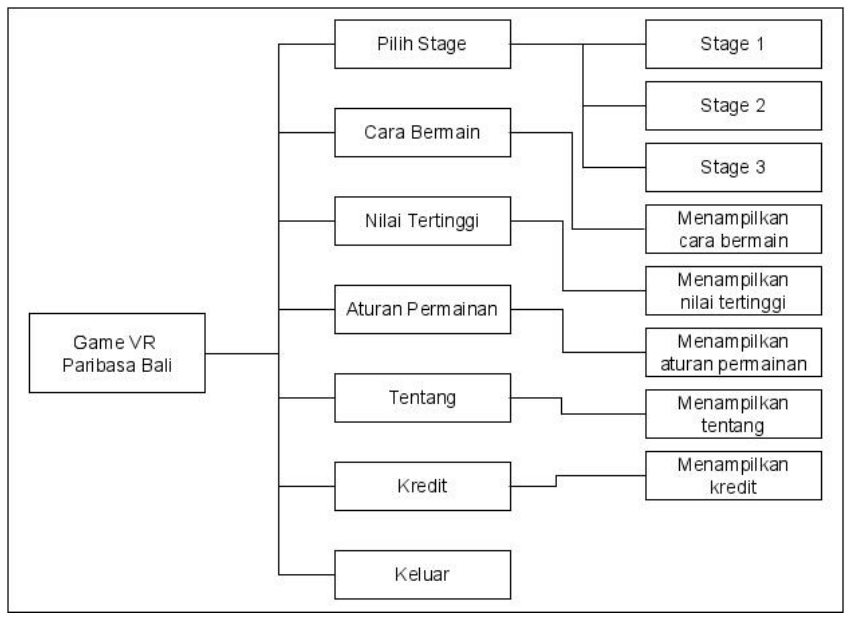

Gambar 6. Struktur navigasi permainan

5. Perancangan Storyboard dan Aturan Permainan

Storyboard adalah sketsa gambar yang disusun berurutan sesuai naskah, storyboard dapat menyampaikan ide cerita kepada orang lain dengan lebih mudah. Adapun storyboard dan aturan permainan dari game $V R$ Labirin ini sebagai berikut:

1. Stage 1

Pada stage 1 ini, pemain akan diberikan pengetahuan tentang paribasa Bali, seperti sesenggakan dan sesonggan melalui buku pengetahuan yang ada dalam labirin.

2. Stage 2

Pada stage 2 ini, pemain akan diberikan pengetahuan tentang paribasa Bali, seperti sloka dan wewangsalan melalui buku pengetahuan yang ada dalam labirin.

3. Stage 3

Pada stage 3 ini, pemain akan diberikan pengetahuan tentang paribasa Bali, seperti bladbadan dan sesawangan melalui buku pengetahuan yang ada dalam labirin.

Sementara itu, aturan permaian yang penulis kembangkan yaitu:

1. Pemain membuka gerbang untuk memulai petualangan

2. Pemain berada dalam suatu ruang labirin.

3. Pemain akan menemukan buku pengetahuan, dimana buku pengetahuan ini nantinya sebagai bantuan untuk menemukan jalan keluar.

4. Setiap buku pengetahuan, memberikan 2 point untuk pemain.

5. Jika pemain melalui jalur yang salah, maka akan diberi peringatan yaitu pointnya akan dikurangi, jika melalui jalan yang salah lagi maka pointnya dikurangi 2.

6. Pemain keluar dari labirin sebelum waktu habis dan mendapatkan bonus poin.

6. Perancangan Antarmuka Perangkat Lunak

Perancangan antarmuka perangkat lunak merupakan proses membangun antarmuka aplikasi yang akan digunakan untuk berinteraksi antara pengguna dengan perangkat lunak. Hasil rancangan antarmuka Game Labirin Berbasis Virtual Reality untuk Pengenalan Paribasa Bali adalah sebagai berikut:

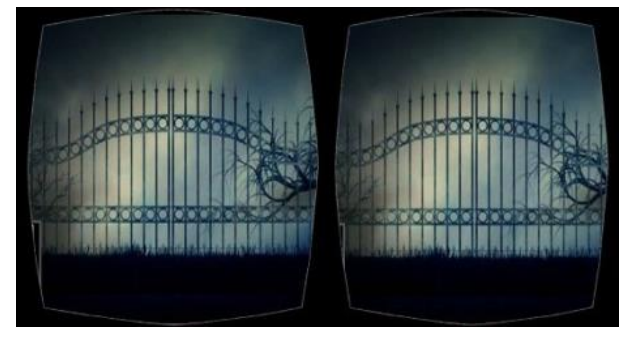

Gambar 7. Rancangan pintu masuk labirin

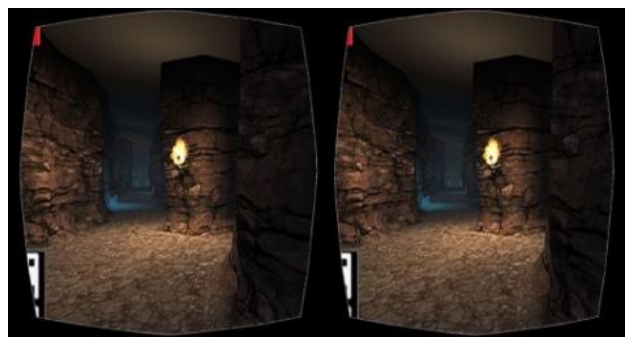

Gambar 8. Rancangan jalur labirin 


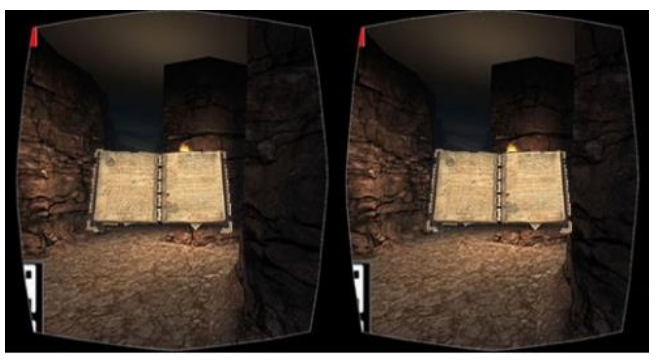

Gambar 9. Rancangan buku pengetahuan

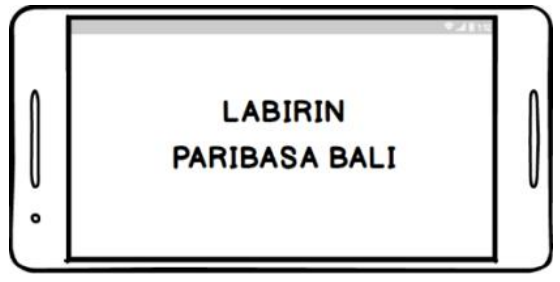

Gambar 11. Splash screen aplikasi

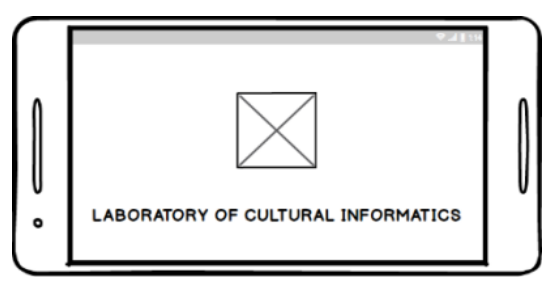

Gambar 13. Logo LCI

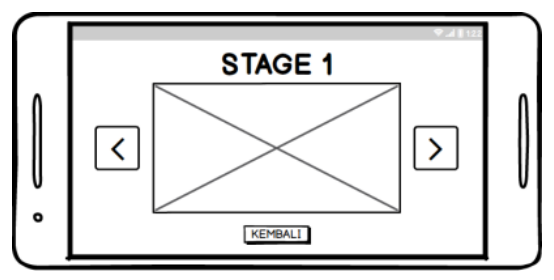

Gambar 15. Stage Labirin

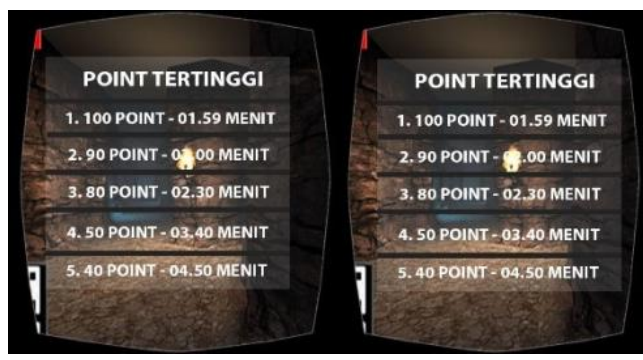

Gambar 10. Rancangan skor tertinggi

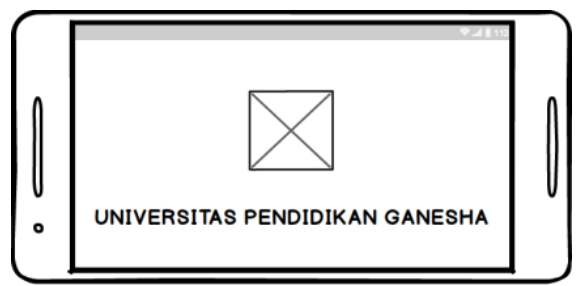

Gambar 12. Logo universitas

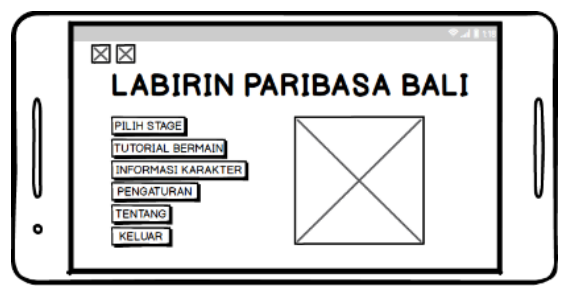

Gambar 14. Tampilan awal aplikasi

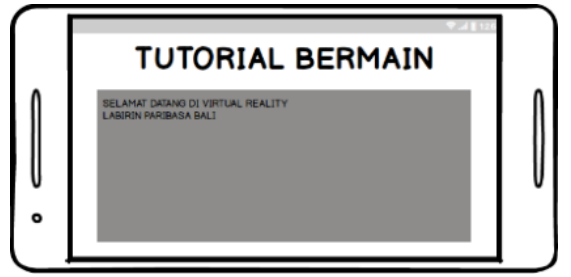

Gambar 16. Cara bermain

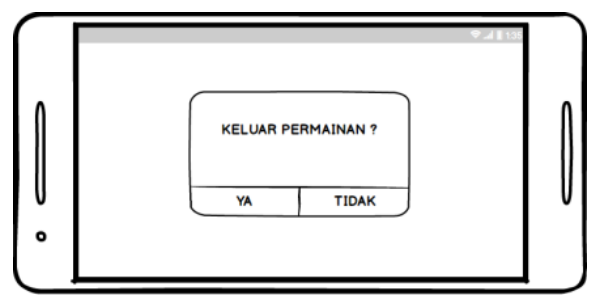

Gambar 17. Menu keluar aplikasi

\section{Development}

Pada tahap development penulis mulai merancang produk dengan menggunakan perangkat lunak dan perangkat keras yang ada. Dalam tahap ini, kerangka yang masih konseptual pada tahap design mulai direalisasikan menjadi produk yang nantinya akan digunakan pada tahap selanjutnya yaitu implementation. 


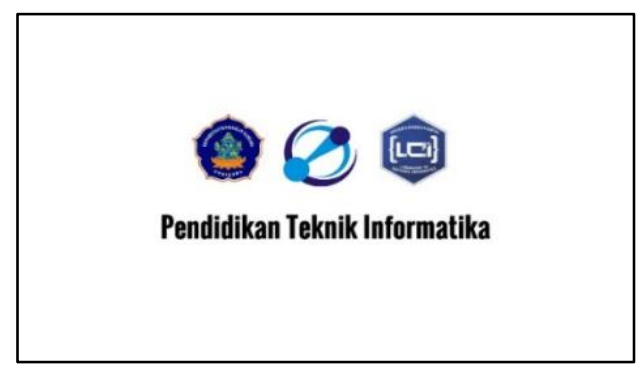

Gambar 18. Hasil rancangan splash screen

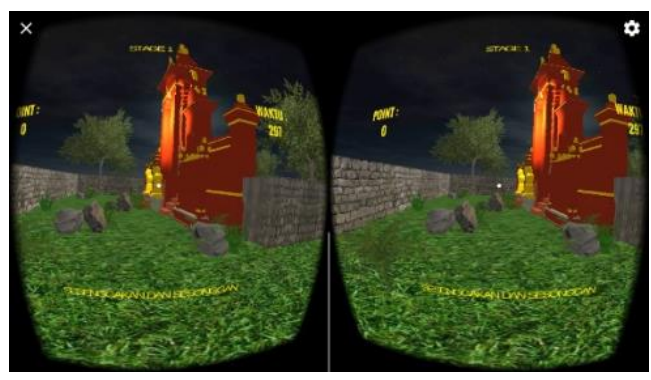

Gambar 20. Hasil rancangan labirin

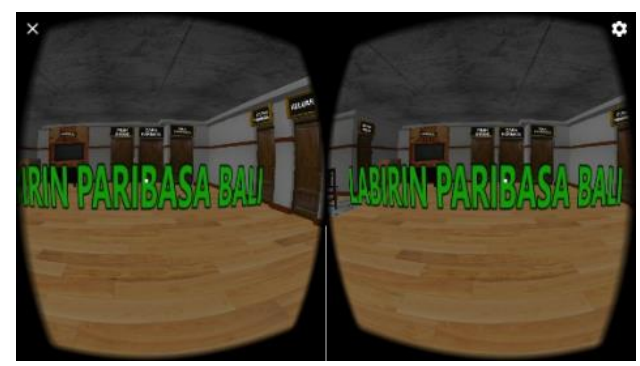

Gambar 19. Hasil rancangan menu awal

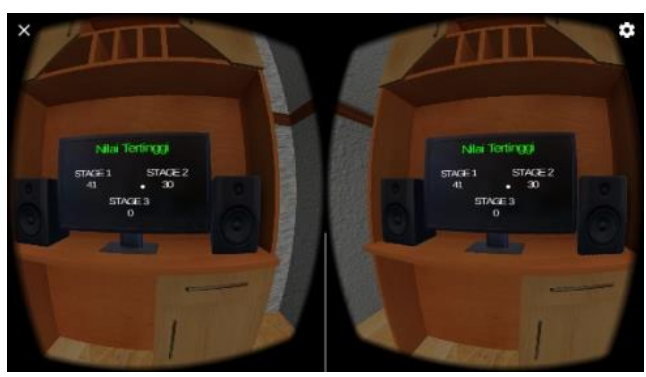

Gambar 21. Hasil rancangan skor tertinggi

\section{Implementation}

Tahap implementasi adalah tahap saat aplikasi telah siap untuk diperkenalkan. Untuk dapat menggunakannya, aplikasi harus dipasang (install) pada perangkat yang sudah disiapkan. Pada tahap ini dilakukan implementasi “Game Labirin Berbasis Virtual Reality untuk Pengenalan Paribasa Bali”.

1. Proses pemasangan aplikasi

Dalam proses instalasi ini penulis menggunakan perangkat smartphone dengan tipe Redmi 4 Prime yang telah memiliki persyaratan minimum untuk menjalankan aplikasi Virtual Reality. File

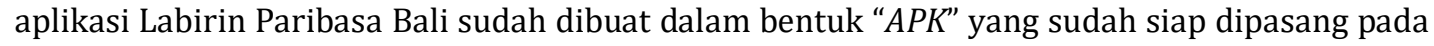
perangkat android.

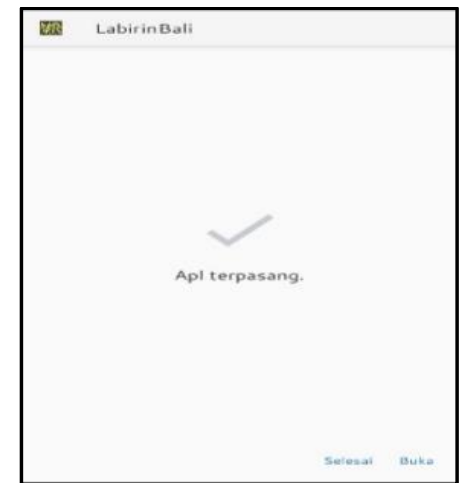

Gambar 22. Pemasangan aplikasi pada perangkat android

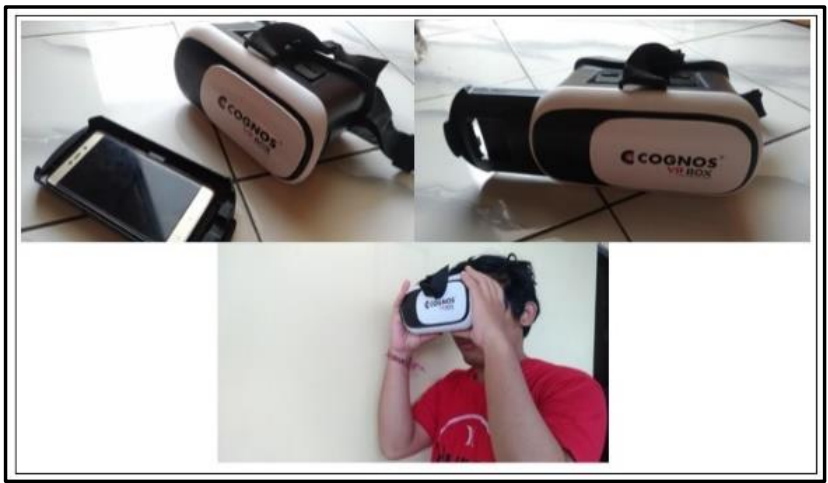

Gambar 23. Penempatan perangkat smartphone pada Virtual Reality cardboard

\section{E. Evaluation}

Berdasarkan metode $A D D I E$, proses evaluasi akan dilaksanakan pada tiap tahap yang telah dilakukan sebelumnya. Evaluasi yang dilakukan berupa pengujian seperti pengujian aplikasi atau penyebaran angket. Hasil evaluasi di setiap tahapan penelitian yang penulis lakukan, dijelaskan lebih lanjut pada sub-bab berikut.

1. Hasil evaluasi tahap analisis.

Pada tahap analisis, hasil yang dievaluasi lebih difokuskan kepada berjalannya kebutuhan fungsional dari aplikasi. Untuk itu penulis membuat sebuah angket "Uji Blackbox" yang berisi 
point - point tentang bagaimana aplikasi berjalan sesuai dengan keinginan. Dalam uji Blackbox ini penulis melibatkan pihak ketiga yaitu pengguna aplikasi. Pada tahapan uji blackbox ini penulis melibatkan 2 responden yang dapat dilihat pada tabel berikut :

Tabel 2. Responden Uji Blackbox

\begin{tabular}{ll}
\hline No & \multicolumn{1}{c}{ Nama } \\
\hline 1 & I Wayan Eka Budi Artawan \\
2 & I Nyoman Jaya Wardhana \\
\hline
\end{tabular}

Pengujian blackbox dilakukan dengan memberikan angket setelah menggunakan aplikasi. Angket yang diberikan memuat pernyataan - pernyataan seperti kesesuaian jalannya aplikasi pada perangkat smartphone, apakah aplikasi dapat dimainkan dengan lancar sesuai dengan apa yang diharapkan dan tampilan tampilan yang muncul pada aplikasi setelah selesai bermain apakah sesuai dengan yang diharapkan. Dari hasil uji blackbox ini secara umum sudah dapat dikatakan sesuai dan memuaskan. Dari 15 butir pengujian didapatkan hasil sebanyak 100\% sesuai.

2. Hasil evaluasi tahap desain.

Pada tahap ini lebih difokuskan kepada evaluasi rancangan tampilan aplikasi yaitu pewarnaan, grafis dan interaktifitas menu dan ikon. Untuk mengevaluasi hal tersebut, penulis melakukan uji ahli media yang melibatkan dua orang dosen yaitu dari Jurusan Teknik Infomatika, Universitas Pendidikan Ganesha yaitu: Made Windu Antara Kesiman, S.T., M.Sc., Ph.D., dan I Made Putrama., S.T., M.Tech. Uji ahli media dilakukan dengan angket.

3. Hasil evaluasi tahap pengembangan.

Pada tahap Pengembangan, hasil yang dievaluasi lebih difokuskan kepada evaluasi isi dari aplikasi, pemakaian kata dan bahasa, dan pembelajaran. Penulis melibatkan Ibu Dewa Ayu Desy Riani, S.Pd. Beliau merupakan seorang penyuluh bahasa Bali yang bertugas di Denpasar. Selain bekerja sebagai penyuluh bahasa Bali beliau juga melakukan konservasi lontar tulisan Bali, identifikasi lontar, membuat kelompok belajar ke sekolah - sekolah (SD, SMP, SMA) dan pasraman tentang bahasa Bali, dan lomba menulis aksara Bali.

4. Hasil evaluasi tahap implementasi

Pengujian kepada pengguna digunakan untuk mengetahui tanggapan dari pengguna setelah menggunakan aplikasi, seperti: kesenangan menggunakan aplikasi, seberapa perlunya aplikasi dalam pengenalan paribasa Bali, kepuasan bermain saat memainkan aplikasi, pemahaman dalam mengenal paribasa Bali melalui aplikasi, kesulitan apa saja yang dilalui pada saat memainkan aplikasi dan juga manfaat aplikasi dalam kehidupan sehari - hari. Uji respon pengguna dilakukan dengan pemberian angket kepada pengguna aplikasi. Angket yang diberikan menggunakan 5 alternatif jawaban yaitu: STS (Sangat Tidak Setuju), TS (Tidak Setuju), KS (Kurang Setuju), S (Setuju) dan SS (Sangat Setuju). Setelah didapatkan respon pengguna selanjutnya dilakukan tahap penghitungan untuk mengetahui persentase dari respon pengguna. Adapun bobot dari uji respon pengguna yaitu dengan pernyataan positif dan negatif dapat dilihat pada tabel 3 .

Tabel 3. Bobot pernyataan

\begin{tabular}{cccccc}
\hline Pernyataan & STS & TS & KS & S & SS \\
\hline Positif & 1 & 2 & 3 & 4 & 5 \\
Negatif & 5 & 4 & 3 & 2 & 1 \\
\hline
\end{tabular}

Perhitungan persentase seluruh responden dihitung menggunakan rumus (Tegeh \& Kirna, 2013).

$$
\begin{aligned}
& \text { Persentase }=\frac{\sum(\text { Jawaban } \times \text { Bobot Tiap Soal })}{n \times \text { Bobot Tertinggi }} \times 100 \% \\
& \text { Persentase }=\frac{\text { Jumlah Persentase Keseluruhan Subyek }}{\text { Banyak Subyek }} \times 100 \%
\end{aligned}
$$

Uji respon pengguna dilakukan dengan cara menyebarkan angket kepada 20 orang dengan rentangan umur 15 - 30 tahun di kalangan pelajar, mahasiswa dan masyarakat. Dari hasil sebaran angket ini mendapatkan hasil sebesar 91\%. Dalam skala Likert termasuk dalam kriteria "Sangat Tinggi". 


\section{SIMPULAN DAN SARAN}

Berdasarkan hasil analisis, desain, pengembangan, implementasi dan evaluasi maka diperoleh kesimpulan sebagai berikut:

1. Perancangan Game Labirin Berbasis Virtual Reality untuk Pengenalan Paribasa Bali telah berhasil dirancang dengan menggunakan model fungsional berupa UML (Unified Modeling Languange) yaitu dengan menggunakan use case diagram dan activity diagram. Game Labirin Berbasis Virtual Reality untuk Pengenalan Paribasa Bali telah berhasil diimplementasikan sesuai dengan rancangan yang telah dibuat sebelumnya.

2. Respon pengguna yaitu masyarakat umum terhadap Game Labirin berbasis Virtual Reality untuk Pengenalan Paribasa Bali mendapatkan respon yang baik. Pengguna sangat tertarik untuk mengenal Paribasa Bali lebih dalam lagi. Dari hasil uji respon di lapangan terhadap 20 orang responden didapatkan hasil sebesar 91\% yang artinya masuk ke dalam kategori sangat baik/sangat tinggi.

Berikut adalah beberapa hal yang dapat dijadikan bahan pertimbangan untuk pengembangan berikutnya yaitu :

1. Desain latar tulisan pada menu utama aplikasi Labirin Paribasa Bali ini penulis nilai masih kurang variatif, akan terlihat lebih baik jika ditambahkan efek visual pada latar tulisannya, sehingga akan menarik untuk dilihat oleh pengguna. Namun tanpa mengurai frame rate aplikasi itu sendiri, agar tetap berjalan dengan lancar.

2. Untuk rintangan pada aplikasi Labirin Paribasa Bali ini masih terbatas yaitu hanya ada 3 rintangan, akan lebih baik jika ditambahkan beberapa rintangan lagi agar pemain tidak cepat merasa bosan.

3. Untuk pencatatan nilai tertinggi pada aplikasi Labirin Paribasa Bali ini masih berupa offline yang hanya bisa dilihat oleh 1 orang pemain saja, alangkah baiknya jika bisa untuk ditambahkan pencatatan nilai tertinggi secara online, dan juga bisa dibagikan ke beberapa sosial media agar bisa dilihat oleh banyak orang.

4. Penulis mendapatkan beberapa keluhan saat memainkan aplikasi ini, yaitu kenyamanan pemain saat bermain seperti pusing, atau mata perih ketika menggunakan perangkat Virtual Reality. Diperlukan waktu istirahat sebelum melanjutkan permainan. Untuk kendala seperti ini penulis menyarankan kepada pengembang selanjutnya agar memperhatikan atau bisa mengantisipasi bagaimana caranya pemain agar bisa nyaman dan tidak merasa pusing saat memainkan permainan ini.

\section{Ucapan Terima Kasih}

Dalam penyusunan skripsi ini, penulis banyak mendapat bantuan dari berbagai pihak, baik itu bantuan moral maupun spiritual. Maka dari itu pada kesempatan ini penulis ingin menyampaikan rasa terimakasih kepada: I Made Ardwi Pradnyana, S.T., M.T., selaku Pembimbing I dan Gede Aditra Pradnyana, S.Kom., M.Kom., selaku Pembimbing II yang telah banyak memberikan bimbingan, arahan, saran dan motivasi dalam proses penelitian yang penulis lakukan. Seluruh staf dosen dan pegawai Fakultas Teknik dan Kejuruan yang telah banyak membantu kelancaran pelaksanaan penelitian ini. Kedua orang tua tercinta penulis yaitu I Gusti Kade Suwerken dan Ni Ketut Sundari yang selalu memberikan kasih sayang, semangat, inspirasi dan tentunya dukungan materi dan non materi sehingga penulis bisa menyelesaikan penelitian ini. Teman - teman sehati, seangkatan dan sepenanggungan yang telah memberi canda tawa pada saat suka maupun duka yang melanda saat menyelesaikan penelitian. Rekan - rekan mahasiswa Jurusan Teknik Informatika yang telah banyak memberikan dukungan dan bantuan serta semua pihak yang tidak dapat penulis sebutkan satu persatu yang telah membantu penyelesaian penelitian ini.

\section{Daftar Pustaka}

Apriyanto, A., \& Lasodi, I. S. (2016). Pembuatan Game Labirin Menggunakan Aplikasi Construct 2 Berbasis Online. Jurnal Elektronik Sistem Informasi Dan Komputer, Volume 2(Nomor 2). Retrieved from file:///C:/Users/USER/Downloads/53-180-1-PB (1).pdf

Bhaskara, S. G. A., Buana, P. W., \& Purnawan, I. K. A. (2017). Permainan Edukasi Labirin Virtual Reality Dengan Metode Collision Detection Dan Stereoscopic. Lontar Komputer, Volume 8(Nomor 2), 65-76. https://doi.org/10.24843/LKJITI.2017.v08.i02.p01

Ganesan, M. (2015). Developing of E-content package by using ADDIE model. International Journal of Applied 
Research, Volume 1(Nomor 3), 52-54. Retrieved from www.allresearchjournal.com

Haviluddin. (2011). Memahami Penggunaan UML (Unified Modelling Language). Memahami Penggunaan UML (Unified Modelling Language), 6(1), 1-15. Retrieved from https://informatikamulawarman.files.wordpress.com/2011/10/01-jurnal-informatikamulawarman-feb-2011.pdf

Indra, D., Darmawiguna, I. G. M., \& Arthana, I. K. R. (2015). "Escape from Ancient Bali” Game Adventure Berbasis Edukasi dan Budaya. Kumpulan Artikel Mahasiswa Pendidikan Teknik Informatika (KARMAPATI), Volume 4(Nomor 5), 422-429.

Jundi, F. Al. (2018). Bahasa Ibu Dari Pandangan Penulis Muda Bali Saat Dialog Sastra di Bentara Budaya. Retrieved from http://bali.tribunnews.com/2018/02/04/bahasa-ibu-dari-pandangan-penulismuda-bali-saat-dialog-sastra-di-bentara-budaya

Kurniawan, A. (2020). Pengertian Budaya Menurut Para Ahli Beserta Definisi Dan Unsurnya. Retrieved June 19, 2020, from https://www.gurupendidikan.co.id/pengertian-budaya-menurut-para-ahli-besertadefinisi-dan-unsurnya/

Marantika, I. M. Y., \& Putra, P. G. P. (2017). Kajian Sosiolinguistik : Model Pemertahanan Bahasa Bali di Lingkungan SMP Negeri 1 Denpasar. Jurnal Tutur, Volume 3(Nomor 2), 740-741.

Prayudi, K. A. W., Arthana, I. K. R., \& Wirawan, I. M. A. (2015). Pengembangan Game Labrin Matematika Tingkat SD. Kumpulan Artikel Mahasiswa Pendidikan Teknik Informatika, 4(5), 414-421.

Putra, D. R., \& Nugroho, M. A. (2016). Pengembangan Game Edukatif Berbasis Android Sebagai Media Pembelajaran Akuntansi Pada Materi Jurnal Penyesuaian Perusahan Jasa. Jurnal Pendidikan Akuntansi Indonesia, Volume 14(Nomor 1), 25-34.

Renavitasari, I. R. D., Irawati, D. A., \& Prasetyo, A. (2016). Pengembangan Game Edukasi Pengenalan Budaya Indonesia “Jelajah" Berbasis Android. Seminar Informatika Aplikatif Polinema 2016, Volume 1, 1-5.

Sulistyowati, \& Rachman, A. (2017). Pemanfaatan Teknologi 3D Virtual Reality Pada Pembelajaran Matematika Tingkat Sekolah Dasar. Jurnal Ilmiah NERO, Volume 3(Nomor 1), 37-44.

Tegeh, I. M., \& Kirna, I. M. (2013). Pengembangan Bahan Ajar Metode Penelitian Pendidikan dengan ADDIE Model. Jurnal Ika, 11(1), 16.

Telusur, R. (2017). Gus Adhi Ajak Generasi Muda Lestarikan Budaya Bali. Retrieved December 27, 2017, from http://telusur.co.id/2017/11/27/gus-adhi-ajak-generasi-muda-lestarikan-budaya-bali/

Tinggen, I. N. (1994). Paribasa Bali. Singaraja: Percetakan Rhika Dewata.

Wati, M. S., Darmawiguna, I. G. M., \& Putrama, I. M. (2016). Pengembangan Game “Meboros Kidang” Sebagai Bentuk Pelestarian Tradisi Meboros di Bali. Kumpulan Artikel Mahasiswa Pendidikan Teknik Inforrmatika (KARMAPATI), Volume 5(Nomor 1), 20-27. Retrieved from https://ejournal.undiksha.ac.id/index.php/KP/article/view/6797 